\title{
Aggregation formation mediated anoikis resistance of BEL7402 hepatoma cells
}

\author{
Zhiyong Zhang ${ }^{*}$, Lihui Han ${ }^{1 *}$, Lili Cao ${ }^{2}$, Xiaohong Liang ${ }^{1}$, Yugang Liu ${ }^{1}$, Hua Liu ${ }^{1}$, \\ Juan Du ${ }^{1}$, Zhonghua $\mathbf{Q u}^{1}$, Changjun Zhu ${ }^{1}$, Suxia Liu ${ }^{1}$, Hui Li ${ }^{1}$, Wensheng Sun ${ }^{1}$ \\ ${ }^{1}$ Institute of Immunology, Shandong University School of Medicine, Jinan 250012, China. \\ ${ }^{2}$ Central Laboratory, Shandong Qianfoshan Hospital, Jinan, 250014, China \\ ${ }^{*}$ Zhiyong Zhang and Lihui Han contributed equally to this work
}

\begin{abstract}
Anoikis resistance is the prerequisite of cancer cells metastasis. Elucidation of the mechanism of anoikis resistance remains a significant challenge. We reported here a model to mimic anoikis resistant process of hepatoma cells in vitro. Experimental results indicated cell to cell aggregation could mediate anoikis resistance of BEL7402 hepatoma cells. Further investigation of these aggregations indicated the biological properties changed greatly after the hepatoma cells lost their anchorage. Aggregation forming process could be separated into three distinct phases according to their biological characteristics, comprising of premature phase, mature phase and postmature phase. Mature phase aggregations have the premium state of cell viability and may mimic the metastatic cells in the circulating system. Biological properties of these three phases aggregations were studied in details including morphological alteration, cell viability and microarray expression profiles. It indicated there was a great upregulation of adhesion molecules during the process of aggregation formation and the cell to cell contact in the aggregation may be mediated independent of calcium involved adhesion pathway. This model might shed light on the anoikis resistance mechanism of hepatoma cells and help to develop new therapies that may target the anoikis resistant hepatoma cells in the metastasis process.
\end{abstract}

Key words: Aggregation - Anoikis - EGTA - Hepatoma

\section{Introduction}

Primary hepatocellular carcinoma (HCC) is one of the leading causes of cancer death worldwide. However, patients do not usually die because of the primary tumor; they die of metastasis involvement of vital organs, and the loss of function that associated with tumor replacement of those vital organs. During the process of metastasis, most of hepatoma cells will die because of anoikis when they invade into the circulation. Only those who can suppress anoikis can survive in the circulation. It is widely accepted that anoikis resistance is the prerequisite of cancer cells' metastasis [1-3].

Anoikis is a Greek word describing a form of apoptosis when cells lost their adhesion to extracellular matrix (ECM) [4]. Many studies have been conducted focusing on cancers' molecular mechanism of anoikis

Correspondence: W. Sun, Inst. of Immunology, School of Medicine, Shandong University, Jinan 250012, China; tel.: (+86531) 88382038, fax.: (+86531) 88380382,

e-mail:wsw@sdu.edu.cn resistance [4-5], including studies on adherent molecules, growth factor receptors, cytoskeletal conformation and so on. However, the mechanism of anoikis resistance remains undefined. Different cancer may experience different processes while getting capability of suppressing anoikis because anoikis resistance is tissue specific and time specific. How could hepatoma cells suffer through matrix detachment in vitro and what may happen in hepatoma's anoikis resistance? This study seeks to develop a model in vitro to mimic the process of hepatoma's anoikis resistance.

\section{Materials and method}

Cell culture and reagents. The human hepatoma cell line BEL7402 was kept in institute of Immunology, School of Medicine, Shandong University. Hepatoma cells were maintained in RMPI1640 (Gibco, Grand Island, N.Y.), supplemented with $10 \%$ fetal bovine serum (FuMeng, Shanghai). Poly-HEMA (Sigma) was prepared by dissolving in $95 \%$ ethanol to a concentration of $12 \mathrm{mg} / \mathrm{ml}$, coated 96-well plate with $0.1 \mathrm{ml} / \mathrm{cm}^{2}$ of surface and allowed to air dry in a sterile environment. Attached and detached BEL7402 cells were generated by sequential cycles of culture on untreated (adhered) and poly-HEMA treated cell culture wells (suspended). Both the detached and attached cells were plat- 
ed at the concentration of $10^{4}$ per well. The three phases of cell were photographed by Nikon Eclipse TE2000-U. The formation of detached cells was maintained in culture under suspended conditions, and individual aggregations for every phase were randomly selected, analyzed and measured in triplicate experiments. The longest diameters of cells with irregular aggregations were determined by NIS-Elements F2.30 software according to the procedure described by Conner [6]. Trypan blue exclusion assay was used to evaluate the viability of cells at different time point, and the morphological changes were recorded by an Optronics digital camera, Nikon 8700.

Calcium deprivation assay. The BEL 7402 cells were plated in 96 well plate at the concentration of $10^{4}$ per well. Both the detached and attached group were serum starved overnight and E-cadherinmediated cell-cell contracts were disrupted by the addition of EGTA to a final concentration of $4 \mathrm{mM}$ according to the procedure describe by Pradeep [7]. Cell viabilities were measured at $1 \mathrm{~h}$ and $3 \mathrm{hrs}$ after calcium deprivation, respectively. The viability of cells was monitored by trypan blue exclusion assay at $1 \mathrm{~h}$ and $3 \mathrm{hrs}$ after calcium deprivation. Images were captured directly from the microscope by an Optronics digital camera, Nikon 8700 .

RNA extraction. In mature phase, just 24 hours after detachment, total RNA was isolated from $0.5 \times 10^{6}$ detached or attached cells using the TRIzol Reagent (Sangon, Shanghai) according to the manufacture's protocol. mRNA was eluted into $40 \mu \mathrm{l}$ of distilled water and stored at $-80^{\circ} \mathrm{C}$ until use.

Microarray. Human oligonucleotide probe arrays (Bioao, Beijing, China) were applied for analysis of mRNA expression levels corresponding to 22000 transcripts. cDNA samples from attached and detached mature phase aggregations were labeled with $\mathrm{Cy} 3$ and Cy5 fluorescent dyes, respectively. DNA microarray hybridization and scanning was performed by Biocapital Campany. Expression profile of detached and attached hepatoma cells were analyzed and compared according to the manufacture's protocol. Genespring 7.2 software was used to mining the data.

\section{Results}

\section{Aggregations formation after detachment}

The procession after detachment of hepatoma BEL7402 cells can be separated into three phases according to their biological features. Premature, mature and postmature phase of cellular aggregations were photographed in Fig. 1B, 1C and 1D. Fig. 1A represents the morphology of normal attached BEL 7402 cell. The dominant biological characteristics of each BEL7402 aggregation phase were summarized in Table 1 and described in details as follows:

1. Premature phase represented the beginning phase of aggregations within the first 8 hours after detachment. BEL7402 cells began to spontaneously self-assemble into small aggregations after lose anchorage (Fig. 1B). Aggregations in this premature phase were only loose associations, and could be easily separated into single cell by regular methods such as EDTA, EGTA, and trypsin digestion.

2. Mature phase aggregations were recorded from the 8th to 36 th hour after detachment. Sizes and densi- ties of aggregations were dramatically increased with time elapse. Average diameters of aggregations increased from $30 \mu \mathrm{m}$ to $200 \mu \mathrm{m}$ during this mature phase. The contact among cells became so tight that it is not easy to separate single cell by regular methods (Fig. 1C).

3. Postmature phase represented the decaying phase of aggregations, from the 36th to 72th hour after detachment. Cell clusters contacted with each other and forming even larger aggregations. Sizes of aggregations were increased by aggregation-aggregation adhesion, and the cells in aggregations underwent compaction. The biggest aggregation could be found in this phase (Fig. 1D).

\section{Detection of cell viability by trypan blue exclusion}

More than $99 \%$ of attached cells could be excluded from trypan blue staining (Fig. 2A). For the premature phase aggregations, BEL7402 cells could resist to anoikis through forming small aggregations. These small aggregations could be excluded by trypan blue to verify their viabilities (Fig. 2B). At mature phase, the aggregations became bigger and bigger and few dying cells can be found around the aggregations (Fig. 2C). At postmature phase, not surprisingly, the dying BEL7402 cells began to appear in the center of aggregations (Fig. 2D). More and more trypan blue stained existing cells and the death could spread to the whole aggregations at the end of post mature phase. The large aggregations were scattered into small pieces which could be dyed by trypan blue. The whole processes of three phases were summarized by cartoon as Fig. 3 .

\section{Cell-cell contraction in aggregations at mature phase resist to the deprivation of calcium}

Compared to attached group without EGTA treatment, the gaps appeared after 1 hour of EGTA treatment, cell-cell contracts were disrupted by EGTA, cells turned round and shrink off from plate (Fig. 4B), while at the same time the cells in aggregations still bound with each other (Fig. 4C). When EGTA treatment was prolonged, the cells in attached group were dyed with trypan blue while aggregations could seldom be dyed.

\section{Microarray results}

Microarray expression profile revealed up regulation of adhesion molecules in mature phase aggregations. Fig. 5 shows the percentage of expression increase. Beta-4 integrin (ITGB4) exhibits 2.14-fold increase while E-cadherin exhibits $33 \%$ increase compare to attached control. The detailed expression values of adhesion molecules were listed in Table 2. 

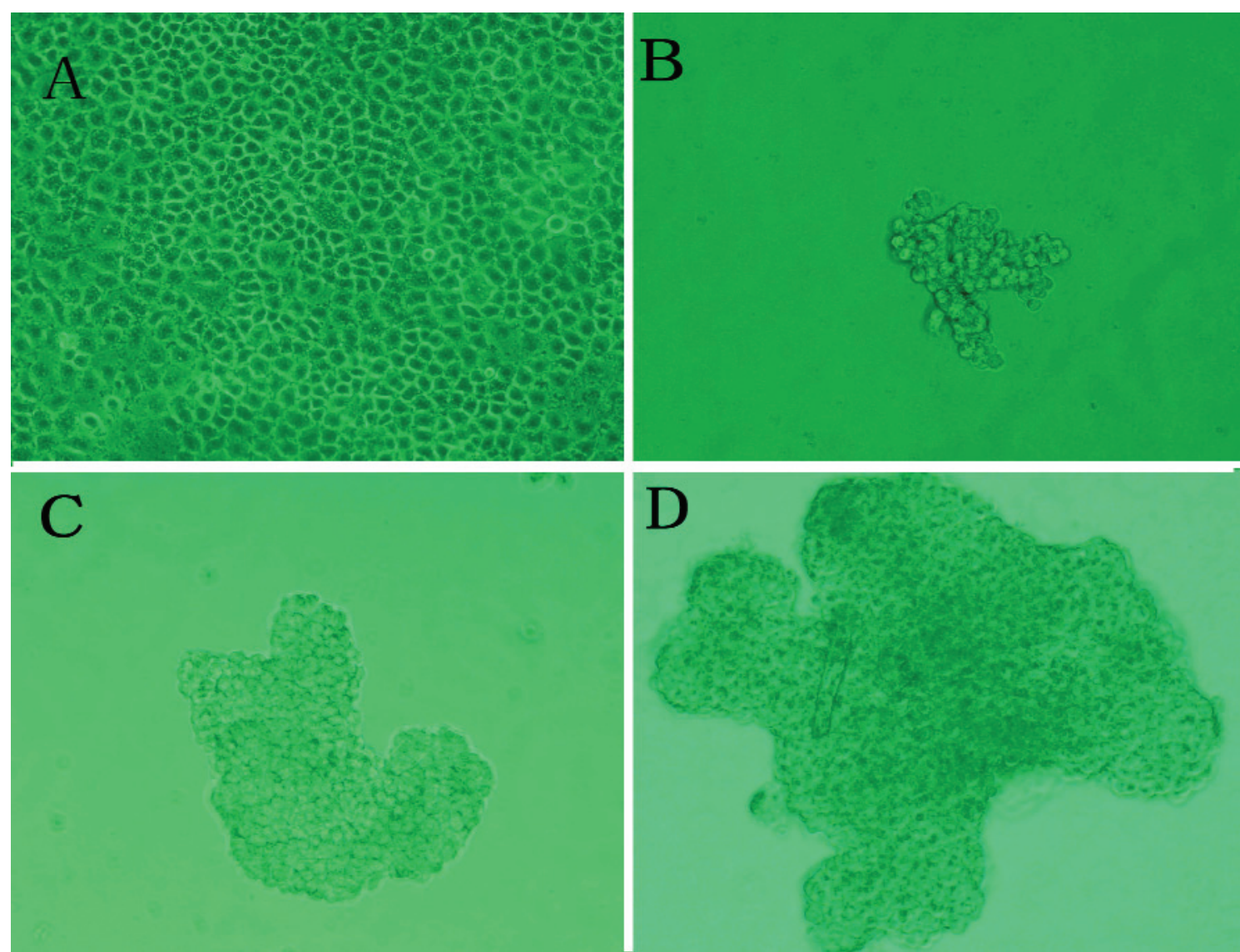

Fig. 1. Attached hepatoma cells and three phases of hepatoma multicelluar aggregations: (A) BEL7402 cells were cultured in attached condition (magnification $\times 100$ ), (B) BEL7402 aggregations in premature phase. BEL7402 cells were self-assembled into loose small aggregations (magnification $\times 100$ ), $(\mathbf{C})$ BEL7402 aggregations in mature phase. BEL7402 cells were self-assembled into strong and compact aggregations (magnification $\times 100$ ), (D) BEL7402 aggregations in postmature phase. The aggregations were compact further, and took on irregular shapes, the biggest aggregation was found in this phase (magnification $\times 100$ ).

Table 1. Characteristics of three phases of hepatoma aggregation.

\begin{tabular}{|l|c|c|c|c|c|c|}
\hline \multicolumn{1}{|c|}{ Phase } & $\begin{array}{c}\text { Cells in every } \\
\text { aggregation }\end{array}$ & $\begin{array}{c}\text { Aggregation } \\
\text { diameters } \\
(\mu \mathrm{m})\end{array}$ & $\begin{array}{c}\text { Cell diameter in } \\
\text { every aggregation } \\
(\mu \mathrm{m})\end{array}$ & $\begin{array}{c}\text { Digestion with } \\
\text { EDTA or tryposin }\end{array}$ & $\begin{array}{c}\text { Resistance to } \\
\text { trypan blue }\end{array}$ & Morphology changes \\
\hline $\begin{array}{l}\text { Premature phase } \\
(0-8 \text { hour })\end{array}$ & $0-50$ & $<100$ & $20-45$ & $\begin{array}{c}\text { Aggregations } \\
\text { can be separated }\end{array}$ & $\begin{array}{c}\text { Rells starting binding } \\
\text { with each another and } \\
\text { forming loose } \\
\text { aggregations }\end{array}$ \\
\hline $\begin{array}{l}\text { Mature phase } \\
(8-36 \text { hour })\end{array}$ & $20-200$ & $50-400$ & $15-30$ & $\begin{array}{c}\text { Aggregations can } \\
\text { not be separated }\end{array}$ & Resist & $\begin{array}{c}\text { Aggregations become } \\
\text { density }\end{array}$ \\
\hline $\begin{array}{l}\text { Postmature } \\
\text { phase (36-60 } \\
\text { hour) }\end{array}$ & $100-500$ & $>400$ & $10-20$ & $\begin{array}{c}\text { Aggregations can } \\
\text { not be separated }\end{array}$ & $\begin{array}{c}\text { The center of } \\
\text { aggregation can } \\
\text { be dyed }\end{array}$ & $\begin{array}{c}\text { The cells were greatly } \\
\text { compact and the biggest } \\
\text { aggregation can be found }\end{array}$ \\
\hline
\end{tabular}

\section{Discussion}

One of the hallmarks of cancer cells is the capability of anchorage-independent growth. In our system, hepatoma cells bound with each other and self-assem- bled into aggregations which compensated suspended cells for depriving of ECM. The sizes of the aggregations were increasing and the cells in the aggregation were compact. The rapid increase in aggregation size was not a function of intercellular growth, but entirely 

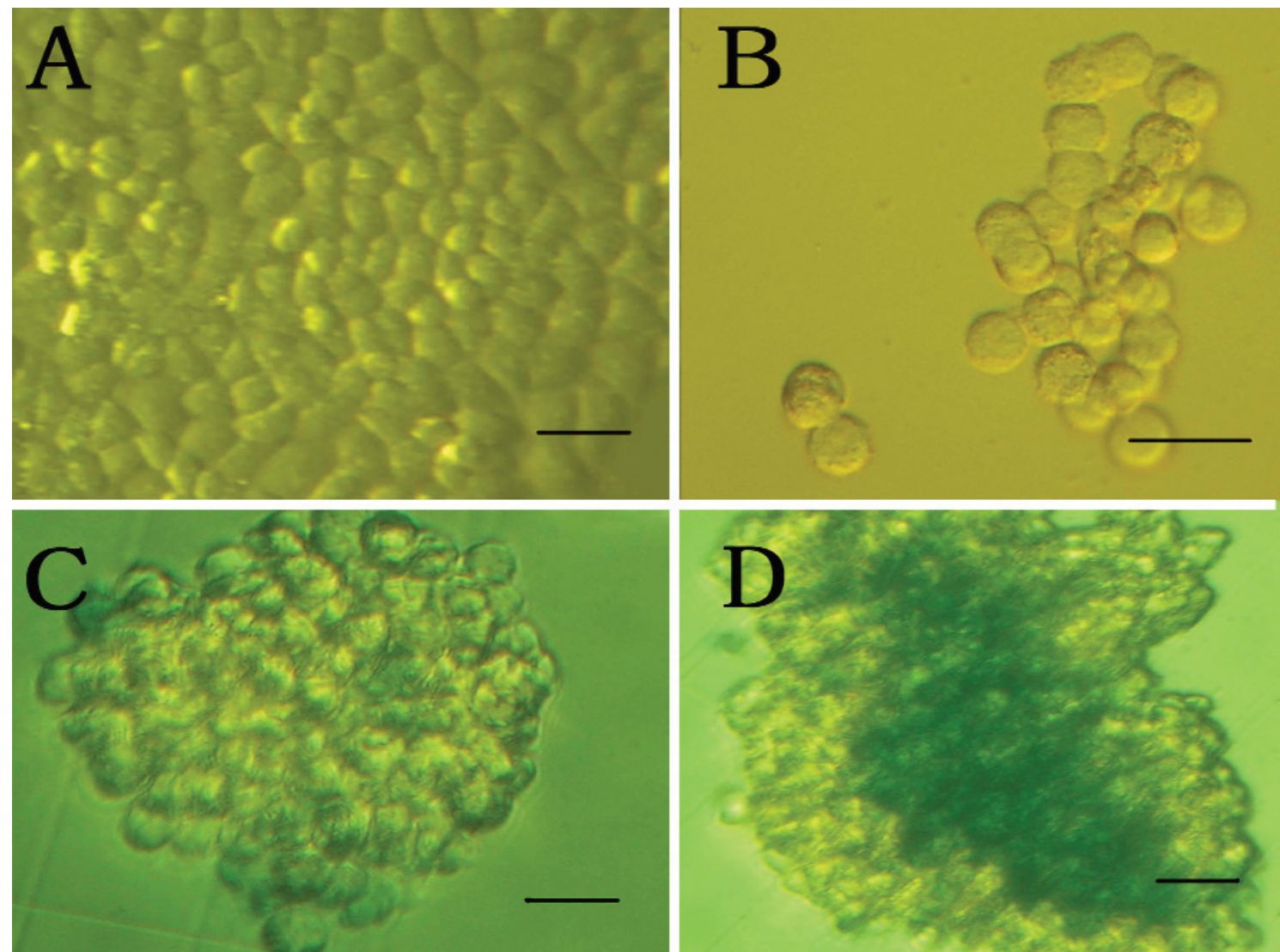

Fig. 2. Detection of cell viability by trypan blue exclusion: (A) attached BEL7402 as the control group, (B) BEL7402 aggregations in premature phase dyed with trypan blue, cells in small aggregations could resist to trypan blue, (C) BEL7402 aggregations in mature phase dyed with trypan blue, aggregations in ripening phase could resist to trypan blue, (D) BEL7402 aggregations in mature phase dyed with trypan blue, the cells in the center of the aggregations were dyed blue. Scale bar $=50 \mu \mathrm{m}$.

\begin{tabular}{|c|c|c|c|c|}
\hline 0 & 0 & 0 & 0 & 0 \\
\hline
\end{tabular}
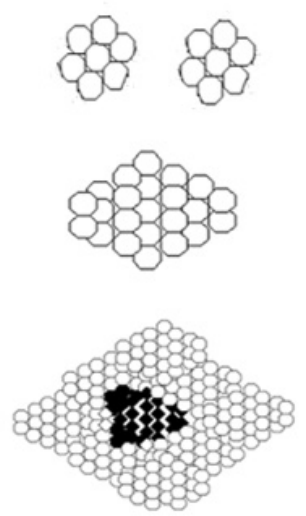

Fig. 3. Procession of aggregations after detachment. A cartoon summarizes the process of BEL7402 cells' aggregation. After BEL7402 cells were detached for 0-8 hours, they spontaneously self assembled and formed loose aggregations as premature phase, During 8-36 hours after detachment, the size of aggregations was increased and cells in aggregations was compacted as mature phase, then death cells appeared in the center of aggregations in postmature phase, until the death spread to the whole cells in aggregations in the end. White circles - alive cells resist to trypan blue. Black circles - dead cell dyed by trypan blue.

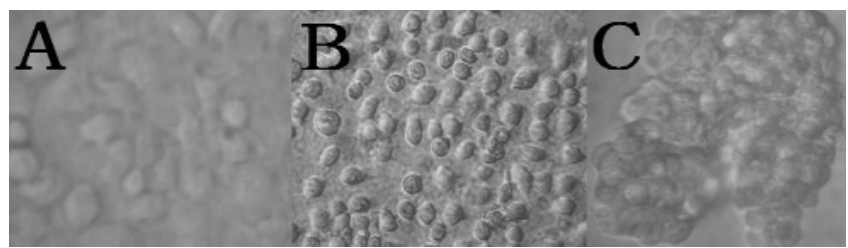

Fig. 4. Calcium deprivation assay: (A) attached BEL 7402 cells as control (magnification $\times 400$ ), $($ B) attached BEL7402 cells treated with 4 mM EGTA for 1 hour (magnification $\times 400$ ), (C) suspended aggregations treated with $4 \mathrm{mM}$ EGTA for 1 hour, no gaps could be found in aggregations (magnification $\times 400$ ).

due to coalescence free cells and small aggregations. These results were highly consistent with the description of prostate cancer cells, DU 145 [7]. In mature phase aggregations, cell-cell contractions became so tight that they could not be easily separated by common separation method such as aspiration, trypsin, and so on. Hepatoma cells in the surface of aggregations might differentiate and exhibit the typical epithelial polarized pattern of adhesion molecules, which functions primarily as a molecular barrier [8]. When such molecular barriers were formed, aggregations could resist to outside stimuli, and protect cells in the center 
Table 2. Up expressed ADM related genes

\begin{tabular}{|l|c|c|c|}
\hline \multicolumn{1}{|c|}{ Name } & $\begin{array}{c}\text { Mature phase } \\
\text { aggregation }\end{array}$ & $\begin{array}{c}\text { Altached } \\
\text { control }\end{array}$ & Description \\
\hline ITGB4BP & 36625 & 28483 & Eukaryotic translation initiation factor 6 (eIF-6) \\
\hline ITGB4 & 2457 & 1150 & Integrin beta-4 precursor (GP150) (CD104 antigen). \\
\hline TGFBI & 1542 & 816 & $\begin{array}{c}\text { Transforming growth factor-beta induced protein IG-H3 precursor (Beta IG-H3) } \\
\text { (Kerato-epithelin) }\end{array}$ \\
(RGD-containing collagen associated protein) (RGD-CAP).
\end{tabular}

of aggregations to metastasis and forming the secondary tumor. On the other hand, the trophic factors in serum were also hard to get into the center of the aggregations. Cells in the center of aggregations were in the circumstance of reduced support of nutrition and oxygen. The hepatoma cells in aggregations could adjust themselves to the new environment actively [9]. These adjustments might include blood vessels formation [10], cell cycle arrest [11], up regulating adhesion molecules to find more support to survive. These adjustments maintained through the mature phase, but in postmature phase, some of the cells in the center of aggregations could not survive through the hypoxia and lack of nutrition, the balance between survival and death signals was broken, the cells would die from the central aggregations and with the elapse of time, the

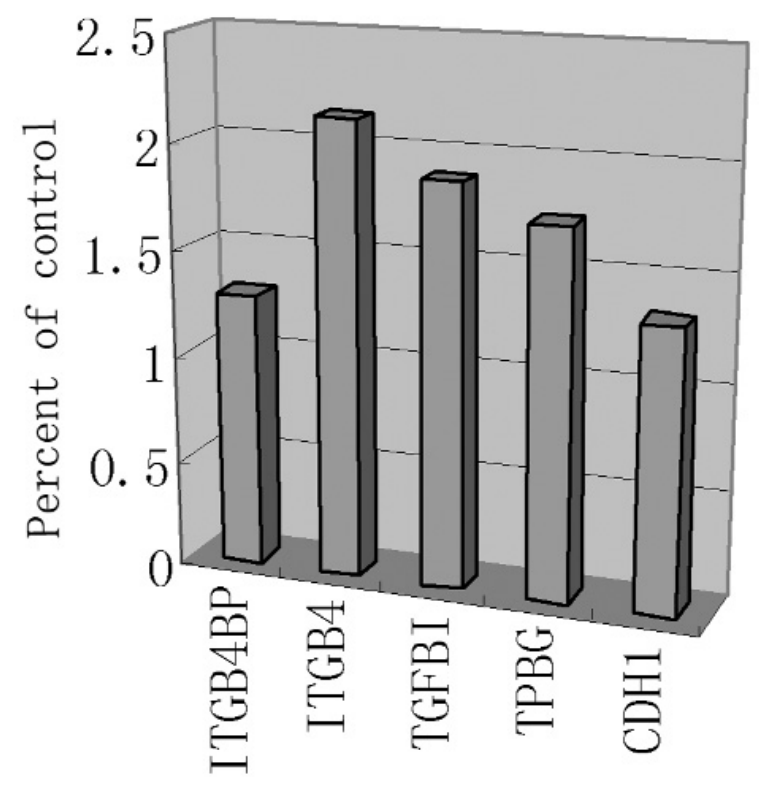

Fig. 5. Increased expressions of adhesion molecules in mature phase aggregations. The adhesion molecules were up regulated in mature phase aggregations, beta-4 integrin (ITGB4) exhibits 2.14fold increase while E-cadherin exhibits 33\% increase compare to attached control. death were spreading to the rest parts until almost all of the cells were dead and the aggregations were disrupted.

Formation of aggregations might be one of the reasons of hepatoma cells' anoikis resistance. In recent years, considerable lights were shed on the mechanism of cell adhesion. Our data indicated cell to cell contraction involved in mature aggregations less dependent on calcium, and was stronger than cell to ECM contraction. Deprivation of calcium for 1 hour, the gaps appeared among attached cells while no gaps could be found in aggregations. When EGTA treatment was prolonged for 3 hours, the cells in attached groups were shrinked off from bottom of plates and were dyed by trypan blue, while most of the cells in aggregations were still alive and bound tightly with each other. These results indicated that aggregations might utilize other survival mechanisms other than calcium-dependent adhesions.

Calcium-dependent adhesion was also important in anoikis resistance. Microarray results suggested that molecules involved in integrin family and cadherin family, which were involved in cell-cell contact or cell-matrix adhesions, were up regulated in our system. Among them, E-cadherin has been best characterized and studied in homotypic cell adhesions [12]. E-cadherin could combine with various growth factor receptors in serum $[13,14]$, phosphorylated TK domain of growth factor receptors and activated downstream signaling pathway and sustained cells' survival and proliferation. Combined with alpha- 6 integrin, beta- 4 integrin was found to be associated with the hemidesmosomes in stratified and transitional epithelia, and was likely to play a pivotal role in the biology of invasive carcinoma [15].

In conclusion, a model had been built to study the mechanism of hepatoma cells' anoikis resistance. The hepatoma cells spontaneously self-assembled into three phases of aggregations after detachment, and the mature phase might have the highest metastasis potential. Study of mature phase aggregations revealed that 
aggregations has stronger adhesion than attached cells, and profiling of mature phase aggregations indicated the up regulation of adhesion molecules were closely involved in hepatoma cells' anoikis resistance.

Acknowledgments: This work was supported by grants from the Natural Science Foundation of China (no. 30700357). The authors gratefully acknowledge Prof. Youhai Chen (Department of Pathology and Laboratory Medicine, University of Pennsylvania, Philadelphia, PA, USA) for valuable help and discussion about this work.

\section{References}

[1] Berezovskaya O, Schimmer, AD, Glinskii AB, Pinilla C, Hoffman RM, Reed JC, Glinsky GV. Increased expression of apoptosis inhibitor protein XIAP contributes to anoikis resistance of circulating human prostate cancer metastasis precursor cells. Cancer Res. 2005;65:2378-2386.

[2] Reddig PJ, Juliano RL. Clinging to life: cell to matrix adhesion and cell survival. Cancer Metastasis Rev. 2005;24:425439.

[3] Geiger TR, Peeper DS. The neurotrophic receptor TrkB in anoikis resistance and metastasis: a perspective. Cancer Res. 2005;65:7033-7036.

[4] Frisch SM, Francis H. Disruption of epithelial cell-matrix interactions induces apoptosis. J Cell Biol. 1994;124:619626.

[5] Grossmann J. Molecular mechanisms of "detachmentinduced apoptosis--Anoikis". Apoptosis. 2002;7:247-260.

[6] O'Connor KC, Venczel MZ. Predicting aggregation kinetics of DU 145 prostate cancer cells in liquid-overlay culture. Biotechnol Lett. 2005;27:1663-1668.

[ 7] Reddy P, Liu L, Ren C, Lindgren P, Boman K, Shen Y, Lundin E, Ottander U, Rytinki M, Liu K. Formation of E-cadherin- mediated cell-cell adhesion activates AKT and mitogen activated protein kinase via phosphatidylinositol 3 kinase and ligand-independent activation of epidermal growth factor receptor in ovarian cancer cells. Mol Endocrinol. 2005;19:25642578.

[ 8] Chan DA, Giaccia AJ. Hypoxia, gene expression, and metastasis. Cancer Metastasis Rev. 2007;26:333-339.

[ 9] Liao D, Johnson RS. Hypoxia: a key regulator of angiogenesis in cancer. Cancer Metastasis Rev. 2007;26:281-290.

[10] Bretland AJ, Lawry J, Sharrard RM. A study of death by anoikis in cultured epithelial cells. Cell Prolif. 2001;34:199210.

[11] Fouquet S, Lugo-Martinez VH, Faussat AM, Renaud F, Cardot P, Chambaz J, Pincon-Raymond M, Thenet S. Early loss of E-cadherin from cell-cell contacts is involved in the onset of Anoikis in enterocytes. J Biol Chem. 2004;279:4306143069.

[12] Fouquet S, Lugo-Martinez VH, Chambaz J, Cardot P, PinconRaymond M, Thenet S. Control of the survival/apoptosis balance by E-cadherin: role in enterocyte anoikis. J Soc Biol. 2004;198:379-383.

[13] Zhou H, Welcher AA, Shooter EM. BDNF/NT4-5 receptor TrkB and cadherin participate in cell-cell adhesion. $J$ Neurosci Res. 1997;49:281-291.

[14] Shen X, Kramer RH. Adhesion-mediated squamous cell carcinoma survival through ligand-independent activation of epidermal growth factor receptor. Am J Pathol. 2004;165:13151329.

[15] Shaw LM, Rabinovitz I, Wang HH, Toker A, Mercurio, AM. Activation of phosphoinositide 3-OH kinase by the alpha6beta4 integrin promotes carcinoma invasion. Cell. 1997;91:949-960.

Submitted: 22 November, 2007 Accepted after reviews: 26 April, 2008 